\title{
Evaluation of Pharmaceutical Waste Disposal Practices in Healthcare Facilities in Lagos State, South West Nigeria
}

\author{
Article by Margaret Okama Obono \\ Master of Public Health, Texila American University, Nigeria \\ E-mail: okamaobono@gmail.com
}

\begin{abstract}
The objective of this study is to find out how unused, expired, damaged and unwanted medicines are handled and disposed of in health facilities in Lagos State, South West Nigeria. An average hospital stocks between 2000 to 4000 drug items for use by patients at any point in time. Hospitals and households have been identified as the largest source of Pharmaceutical waste going into the sewer system.

A large quantity of Pharmaceutical Waste generated in hospitals include regulated hazardous and non-regulated hazardous Pharmaceutical waste and a significant amount of these have been found in underground water and drinking water.

195 health facilities made up of 5 tertiary teaching/specialist hospitals, 25 secondary healthcare facilities and 165 primary healthcare centres were evaluated using structured questionnaires to collect data. Data were analyzed using SPSS version 20.

Results show that $85 \%$ of disposal of pharmaceutical waste was done by open burning, a method that causes air pollution. There was no significant association between category of Health Facility and method of disposal of pharmaceutical waste. Less than 10\% of Health Facilities had Pharmaceutical Waste Disposal(PWD) programmes in place.15\% of respondents see the need for designated drug take - back centres and will consider establishing one. The need for additional training on PWD was identified.
\end{abstract}

Keywords

1. PHARMACEUTICAL WASTE:- Solid, liquid or gas waste from Pharmaceutical products that can pose a substantial hazard to human/animal health and the environment when not properly managed (40 CFR part 261).

2. HAZARDOUS WASTE:- Wastes with properties that make the product dangerous or potentially harmful to human health or the environment.

3. HAZARDOUS WASTE LANDFILL:- A disposal facility where hazardous waste is placed in a land treatment facility, a surface impoundment, an underground injection well, a salt dome formation, a salt bed formation, an underground mine, a cave or a corrective action management unit (40 CFR 260.10)

4. DRUG TAKE -BACK EVENTS: - Any programme or series of programmes organized by the Drug Enforcement Administration (DEA).Drug takes back initiative on which the public can return unwanted, unused or expired drugs.

5. LISTED HAZARDOUS WASTES:- Materials specifically listed by regulatory authorities as waste from non-specific sources, specific sources or discarded chemical product.

6. OTC MEDICINES:- Over -the- counter drugs that can be sold directly to a client without a prescription from a healthcare professional.

\section{Introduction}

Pharmaceuticals include but are not limited to prescription medicines and over-the-counter (OTC) remedies, veterinary medicines, nutritional supplements, herbal medicines, various alcoholic and non-alcoholic beverages and drugs of abuse that are used for non-medical purposes. Any unused, expired, damaged, deteriorated drug or product as listed above becomes Pharmaceutical Waste. 
Texila International Journal of Public Health

Volume 4, Issue 4, Dec 2016

Pharmaceutical Waste can be put into the following groups:-

- Hazardous Wastes e.g. Carcinogenic or Mutagenic agents.

- Non - hazardous Wastes e.g. non-carcinogenic, they constitute the largest group of Pharmaceutical Waste.

- Not pharmaceutically active waste e.g. dietary supplements, intravenous fluids.

- Flammable, irritant, harmful, oxidizing or Eco-toxic medicines e.g. disinfectants.

An average hospital pharmacy stocks between 2000 and 4000 different pharmaceuticals products for use of patients. This number of pharmaceuticals is continuously on the increase due to research and development of new drugs annually and these results in a corresponding increase in pharmaceutical waste. Hospitals and households have been identified as the largest source of Pharmaceutical Waste going into the sewer system. Hospital and healthcare facilities may fall into one of these two groups in generation of Pharmaceutical Waste.

1. Large Quantity Generators(LQGs):- Facilities that generate greater than or equal to $1000 \mathrm{~kg}$ of hazardous Waste per calendar month or greater than $1 \mathrm{~kg}$ of acute hazardous waste per calendar month.

2. Small Quantity Generators (SQGs) :- Facilities that generate between $100 \mathrm{~kg}$ and $1000 \mathrm{~kg}$ of hazardous waste per calendar month and accumulate less than $6,000 \mathrm{~kg}$ of hazardous Waste at any time or generate $1 \mathrm{~kg}$ or less of acutely hazardous waste per calendar month.

The Pharmaceutical Waste generated in most cases is burnt, buried or poured down the drain.

Disposal methods that have been utilized for unwanted pharmaceuticals are:

- Return to donor or manufacturer

- Dispose through landfill

- Waste immobilization: encapsulation or inertization

- Through server system

- Burning in open containers

- Medium temperature incineration

- Novel high temperature incineration

- Chemical decomposition

Improper disposal of Pharmaceuticals may have the following consequences:-

- Contamination of underground water.

- Contamination of drinking water

- Lead to accidental ingestion by children or pets

- Lead to unintended use and misuse of medicines

- Expired medicines may be diverted and rebelled for sale

- May cause damage to aquatic life

- Some pharmaceuticals kill bacteria necessary for treatment of sewage.

- Disposal of pharmaceuticals by burning may cause a release of toxic pollutants into the air.

- There may be development of antibiotic resistance due to ingestion from animals that have been continuously exposed to antibiotic waste in the environment.

It is dangerous to allow unqualified persons to handle the Pharmaceutical Waste. Pharmaceutical Waste Management is especially challenging given the complexity of the regulations that govern its activities and the multiple regulatory agencies that oversee Waste Management.

In the United States, Pharmaceutical Waste Management is regulated by agencies such as:-

- Environmental Protection Agency (EPA)

- Department of Transportation (DOT)

- Drug Enforcement Administration(DEA)

- Occupational Safety and Health Administration (OSHA)

- Pharmacy Board 
In the United States treatment, storage and disposal of hazardous waste are regulated under the "Resource Conservation and Recovery Act" (RCRA) in 40 CFR 261 where they are divided into 2 major categories. ${ }^{3}$

1. Characteristic Waste:- According to the characteristic exhibited by the chemicals like: ignitability, reactivity, corrosivity\& toxicity.

2. Listed Hazardous Wastes are materials specifically listed by regulatory authorities as hazardous wastes which are from non-specific sources, specific sources or discarded chemical products.

Hazardous waste can be in different physical states:- gaseous, liquid or solid. They cannot be disposed of like any other waste from households. Their disposal is complex and expensive.

\section{Disposal of Hazardous Waste}

- Disposal in landfills: Some disposed hazardous waste in landfills eventually enter to the natural hydrologis system. Thus many landfills now require counter measures against ground water contamination. Barriers are installed along the foundation of the landfills to absorb these chemicals. Currently hazardous waste must be stabilized and solidified and must undergo treatment before disposal. Flammable materials can be recycled into industrial fuel.

- Cement Based Solidification and Stabilization is a method used to treat range of hazardous waste by improving physical characteristics and decreasing the toxicity and transmission of contaminants. The process converts sludge into cement and pharmaceutical hazard adjustment agents added (phosphates or sulfur) to reduce settling time, increase the compressive strength or reduce the leach ability of contaminants.

- Incineration, destruction and waste to energy. Incinerating at high temperature is a method of disposal of hazardous waste. Current technology has developed more efficient incinerators that control the emission of toxic gases. Different incinerators are used depending on the characteristics of the waste. Today incineration treatment is also used to generate energy from the gases released in the process.

- Pyrolysis:-Some hazardous waste like concentrated organic waste, pesticides, organic pollutants can be eliminated using pyrolysis in ultra high temperature electrical arc, in inert conditions to avoid combustion.

\section{Objectives of Study}

1. To assess the method of Pharmaceutical Waste disposal in healthcare facilities in Lagos State.

2. To determine the association between the methods of pharmaceutical waste disposal and the categories of healthcare facility.

3. To find out if Pharmacists working in these health facilities have received additional training on Pharmaceutical Waste Disposal.

4. To know if there are Pharmaceutical Waste Management programs in these healthcare facilities.

5. To know if there are designated centres for recall/take-back of expired and unused drugs in these health facilities.

\section{Method of Study}

Study Design:- This is a cross sectional descriptive survey that was done using structured questionnaire to collect data from various healthcare facilities in Lagos State.

Study Location and Population:- Lagos State is located in the Southwestern geopolitical zone of Nigeria. It is the smallest of the 36 states of Nigeria and has an area of $3577 \mathrm{~km} 2$ and a population of 17,552,940 as at 2012 census. It however contains the largest urban city and is claimed to be the economic nerve centre at the country. 
Texila International Journal of Public Health

Volume 4, Issue 4, Dec 2016

There are 6 tertiary/specialist hospital, 26 secondary hospitals and 288 primary healthcare centres that are run by the government of Lagos State to serve the population. Most of these primary health centres are located in the rural areas and high density populated area.

Sample size determination: The sample size of the number of health facilities to collect data from was calculated using the formula:-

$$
\mathrm{n}_{\mathrm{o}}=\mathrm{z}^{2} \mathrm{pq} / \mathrm{e}^{2}
$$

Where:-

$$
\begin{array}{lll}
\mathrm{n}_{\mathrm{o}} & = & \text { sample size } \\
\mathrm{Z} & = & \text { confidence level taken as } 1.96 \\
\mathrm{P} & = & \text { variability taken as } 0.5 \\
\mathrm{q} & = & 1-\mathrm{p} \\
\mathrm{e} & = & \text { desired level of precision taken as } \pm 5 \%
\end{array}
$$

Then the minimum required sample size $\mathrm{n}$, by the finite population correction for proportions

$$
\mathrm{n}=\mathrm{n}_{\mathrm{o}} / 1+\mathrm{n}_{\mathrm{o}}-1 / \mathrm{N}
$$

Where $\mathrm{N}=$ population of healthcare facilities (HC)

\section{Calculated sample size}

\begin{tabular}{|l|l|l|}
\hline Types of HF & Number of HF Lagos State & Minimum required sample size \\
\hline Tertiary hospitals & 6 & 5 \\
\hline Secondary HF & 26 & 25 \\
\hline $\begin{array}{l}\text { Primary healthcare } \\
\text { centers }\end{array}$ & 288 & 165 \\
\hline & & 195 total \\
\hline
\end{tabular}

\section{Research Instrument for Data Collection}

The study utilized structured questionnaires consisting of both closed and open ended questions. It was made up of two sections. The first section was to identify the category of health facility and give the demographics of the Drug Manager or in each of these health facilities. It also sort to assess the type of additional training acquired on Pharmaceutical Waste Management.

The second section had questions to assess the actual practice of disposal of pharmaceutical waste to determine availability of drug take-back centres and pharmaceutical waste management programs in each of these facilities.

The responses from the retrieved questionnaires were examined and a coding scheme prepared to facilitate analysis of data. Data entry, cleaning and analysis was done using the statistical package for social sciences (SPSS.20).

Descriptive Statistics, frequencies and percentages, as well as inferential statistics were generated.

Limitation of the Study:- This study was carried out in Lagos and may not be a reflection of pharmaceutical waste disposal in other parts of the country. It also did not assess the health impact of improper waste disposal.

\section{Results}

A total of 195 questionnaires were distributed to the government owned health facilities in Lagos State. All the questionnaires to the tertiary HF and secondary HF were retrieved. Due to the short period used for the study and large spread of the primary HF only 105 of the questionnaires were retrieved.

The percentage of response was $69.2 \%$. Some of the questionnaires were not properly filled and so could not be utilized.

Distribution of Health Facilities showed a $77.8 \%$ of respondents from primary HF, $18.5 \%$ from secondary health facilities and $3.7 \%$ of respondents from tertiary health facilities. (Figure 1) 
Demographic Characteristics:- Results showed a 1.3 ratio of male (27\%) to female (73\%) respondents. (Figure 2) Majority of respondents are of middle age between 31 -50 years (70\%). (Figure 3)

The designations/rank of Pharmacists in charge of drug management in these health facilities showed that almost $40 \%$ of respondents are in the directorate cadre (Administrative cadre) and all of these officers are managers of either the tertiary or secondary health facility. None of the primary health facilities were headed by a Director of Pharmacy. On qualification, results showed that all the respondents either had a first degree or postgraduate qualification in Pharmacy.

In the area of number of years of experience, $25 \%$ of respondents had between 5-9 years of experience, $26.8 \%$ had between 10-14years of experience in practice, 25\% had $15-19$ years and $22.3 \%$ had more than 20 years of professional experience. (Figure 4) Only $11 \%$ of all these respondents agreed to having had any form of additional training on Pharmaceutical Waste disposal/management. (Figure 5)

\section{Pharmaceutical Waste Disposal Practice}

Results show that in about $85 \%$ of the health facilities collation and disposal of pharmaceutical waste was done once in 6 months or one year. Disposal was by burning. (Table 3)

Donated drugs or drugs used for research or programs were returned to the donors on expiry to reduce the value of expired pharmaceuticals in the facilities at any point in time.

Only the few tertiary health facilities had stock of expired hazardous pharmaceuticals (4\%) (Figure 6).

Only $8 \%$ of the respondents agreed to having a pharmaceutical waste disposal programs in their health facilities (Figure 8). No health facility currently has an established drug take back program/centre, (Figure 7) but 15\% of respondents agree that recall of expired/unwanted drugs is necessary and they will consider the establishment of a centre.

Association between method of disposal of pharmaceutical waste and grade/category of health facility.

Results show that the common method of disposal which is burning was practiced by all categories of healthcare facilities(Figure 9). Therefore there was no significant association between the category of HF and disposal method.

\section{Discussion}

The increasing number of both hazardous and non-hazardous drugs in circulation and the consequent increase in amount of expired, damaged and unwanted pharmaceutical wastes are disposed of.

Expired and unused drugs in households as well as those generated in health facilities pose a serious danger to humans and the environment if not properly disposed of.

This study revealed that both hazardous and non-hazardous drugs are utilized in the three categories of health facilities and Pharmaceutical Waste generated includes both hazardous (4\%) and non-hazardous (96\%) waste. There is need to ensure that Pharmaceutical Waste are disposed of properly to avoid the numerous consequences of inappropriate disposal.

The study revealed that very senior professionals with several years in practice are responsible for drug management in all the facilities studied. This however did not confer expert knowledge of pharmaceutical waste disposal. Healthcare professional : doctors, pharmacists, nurses etc do not receive the training on hazardous waste management during their training so they need additional training on pharmaceutical waste management practice. Safety and Environmental Services Managers who receive training in Waste Management may not be familiar with the active ingredients of these pharmaceutical products and the level of toxicity so may not be able to treat them appropriately.

On the actual practice of disposal, 85\% of the Pharmaceutical Waste was disposed by burning and burying. Studies have shown that expired drugs buried or put in landfills 
Texila International Journal of Public Health

Volume 4, Issue 4, Dec 2016

eventually leach into ground water and drinking water. The drugs burnt in open air cause a release of pollutants into the atmosphere posing a health hazard. Proper disposal of Pharmaceutical Waste may be expensive because of the numerous regulatory agencies controlling these processes, but there are currently numerous methods of proper disposal of Pharmaceutical Waste.

The study revealed that very few health facilities (8\%) have documented pharmaceutical waste management programs in place. This should be given priority and the regulatory agencies should enforce its implementation considering the dangers of inappropriate disposal of Pharmaceutical Waste.

A Large amount of expired and unwanted Pharmaceuticals are in households with people who have recovered or whose prescriptions were changed and they do not need those drugs. There is virtually no drug take-back centres designated in the Pharmacies of healthcare facilities as revealed by this study. Establishment of these centers will reduce the practice of pouring drugs down the drain or putting them into the trash can. There is need to encourage patients to return their unwanted medicines to designated centers for proper disposal.

There was no association established between the category of health facility and the method of pharmaceutical waste disposal. The primary HF in rural areas and tertiary HF in the urban area all dispose of by burning or burying. The study did not identity any association between the educational qualification or number of years of professional experience and the methods of Pharmaceutical Waste disposal.

\section{Conclusion}

The disposal of Pharmaceutical Waste especially hazardous Pharmaceutical Waste is a complex procedure that requires specific training of healthcare professional to carry out. Most healthcare professionals currently managing medicines in Lagos State healthcare facilities do not have adequate training to handle the appropriate disposal of pharmaceutical waste.

There is need to put in place a plan to give/organize additional periodic training for Drug managers in all health facilities in Lagos State.

This study revealed that most of the Pharmaceutical Waste being generated by healthcare facilities in Lagos State is currently not being properly disposed of and may pose a health hazard in future. There was no association identified between the category of healthcare facility (tertiary, secondary or primary) and the method of disposal of pharmaceutical waste. All the health facilities used the same method of disposal.

There is standardized documented Pharmaceutical Waste management program in existence and there is need to put one in place.

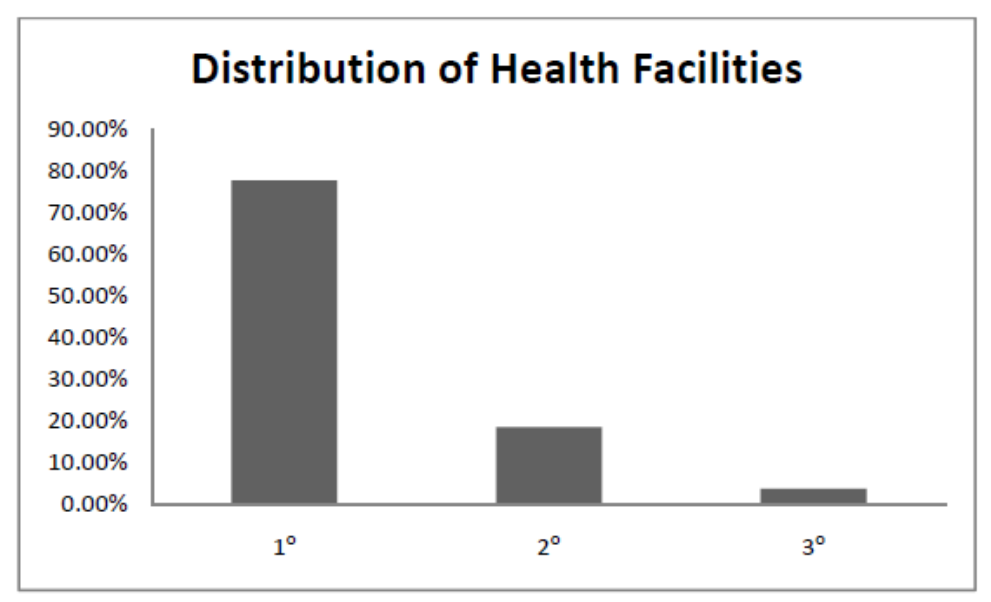

Figure 1 
TABLE 1

\begin{tabular}{|c|c|}
\hline \multicolumn{2}{|c|}{ DESIGNATION OF RESPONDENTS } \\
\hline Pharmacists cadre & $61.30 \%$ \\
\hline Director Cadre & $38.70 \%$ \\
\hline
\end{tabular}

Gender of

Respondents Gender of Respondents

$0 \%$

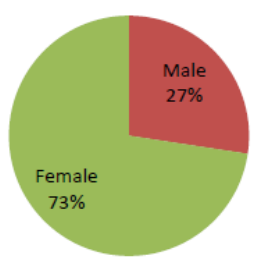

FIGURE 2

TABLE 2

\begin{tabular}{|c|c|}
\hline \multicolumn{2}{|c|}{ Highest Professional Qualification } \\
\hline BPharm & $46.50 \%$ \\
\hline 2nd Degree & $53.50 \%$ \\
\hline PhD & $0 \%$ \\
\hline
\end{tabular}

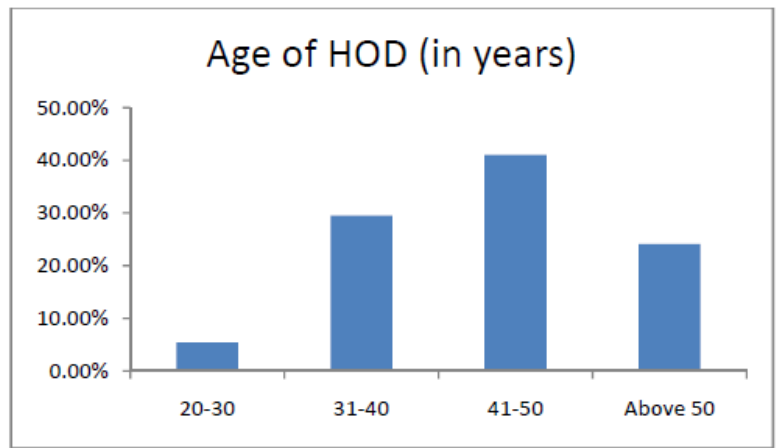

FIGURE 3

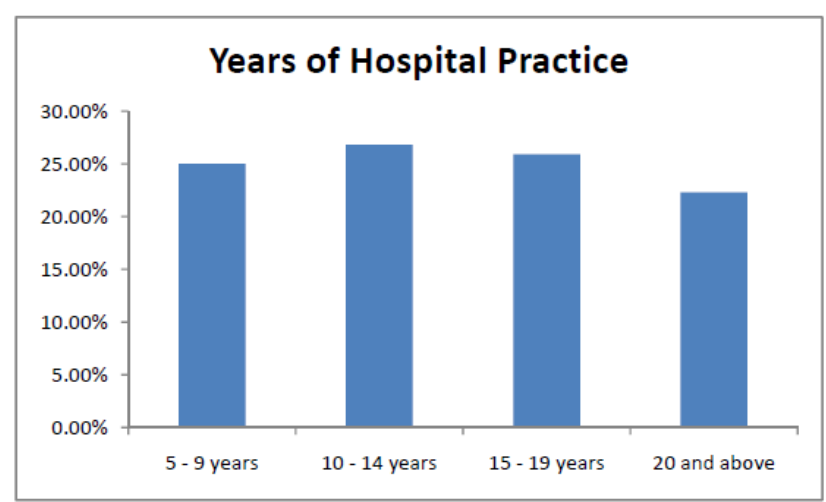

FIGURE 4 
Texila International Journal of Public Health Volume 4, Issue 4, Dec 2016

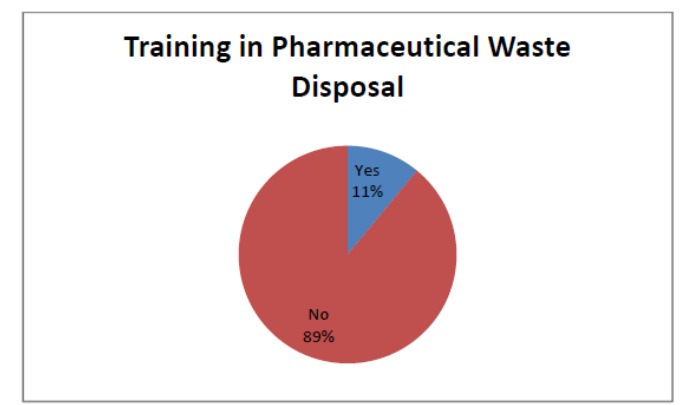

FIGURE 5

TABLE 3

\begin{tabular}{|c|c|}
\hline \multicolumn{2}{|c|}{ Frequency of Drug Disposal } \\
\hline Never & $6.45 \%$ \\
\hline Under a month & $3.60 \%$ \\
\hline 1 - 3 months & $4.50 \%$ \\
\hline 4 - 6 months & $40.00 \%$ \\
\hline 6 months to 1 year & $45.50 \%$ \\
\hline
\end{tabular}

\section{Harzadous Drugs among Items \\ Boarded}

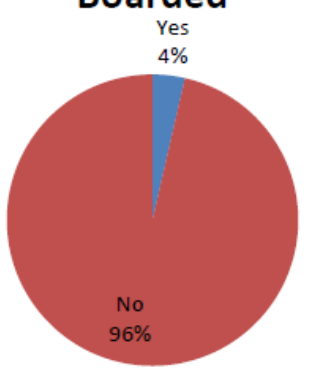

FIGURE 6

TABLE 4

\begin{tabular}{|c|c|}
\hline \multicolumn{2}{|c|}{ Method of Disposal } \\
\hline Burn & $85.50 \%$ \\
\hline Bury & $2.70 \%$ \\
\hline Incinerate & $1.80 \%$ \\
\hline Pour down the drain & $2.70 \%$ \\
\hline Put into trash & $0 \%$ \\
\hline Send to landfill & $4.60 \%$ \\
\hline Others & $2.70 \%$ \\
\hline
\end{tabular}




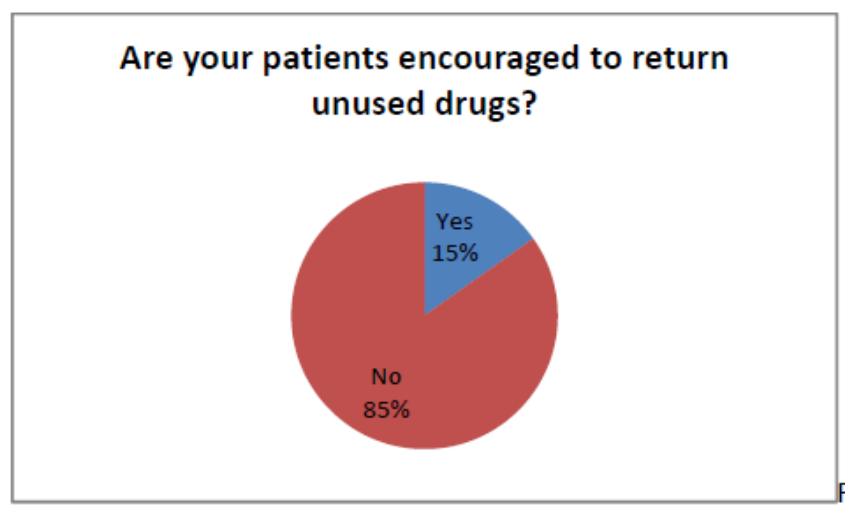

FIGURE 7

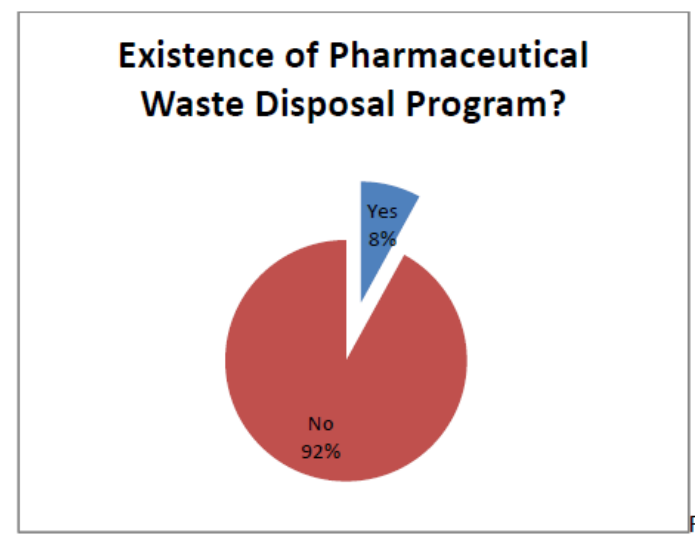

FIGURE 8

Method of Pharmaceutical Waste Disposal within Healthcare Facilities

TABLE 5

\begin{tabular}{|c|c|c|c|}
\hline & $1^{0} \mathrm{HCF}$ & $2^{\circ} \mathrm{HCF}$ & $3^{\circ} \mathrm{HCF}$ \\
\hline Burn & $82.60 \%$ & $81.50 \%$ & $20.00 \%$ \\
\hline Bury & $0 \%$ & $4 \%$ & $40 \%$ \\
\hline Incinerate & $0 \%$ & $0 \%$ & $20 \%$ \\
\hline Pour down drain & $0 \%$ & $11 \%$ & $0 \%$ \\
\hline Trash In bin & $0 \%$ & $0 \%$ & $0 \%$ \\
\hline Send to Landfill & $5.80 \%$ & $0.00 \%$ & $0.00 \%$ \\
\hline Others & $11.60 \%$ & $3.70 \%$ & $20.00 \%$ \\
\hline
\end{tabular}

FIGURE 9

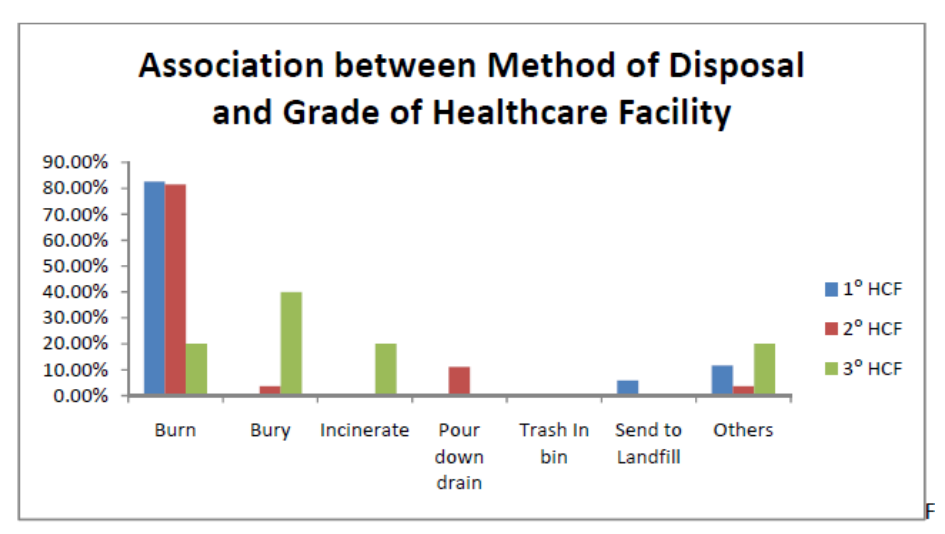


Texila International Journal of Public Health

Volume 4, Issue 4, Dec 2016

\section{References}

[1] 40 CFR 261

[2] Barbalace, Roberta Crowell (2003 - 08-01). The History of Waste” Environmental

Chemistry.com. Retrieved 2013 -12-09

[3] Chaudhary R, Rachana M.,2006. "Factors affecting hazardous waste solidification/stabilization". A review in Journal of Hazardous Materials B137pp.267-276

[4] Encyclopedia Britannica

[5] Guidelines for the safe Disposal of unwanted Pharmaceuticals in and after Emergencies

[6] Glossary of Environment Statistics: Series F. No.67/Department for Economic and Social Information and Policy Analysis, United Nations. New York: UN 1997

[7] Hazardous Waste Landfills

[8] Land Disposal Restrictions for Hazardous Waste

[9] RESEM Waste Tyre Pyrolysis Plant in USA, retrieved 2011-10-24

[10] "Resource conservation and Recovery Act” US EPA

[11]The US. EPA’s Hazardous Waste Cleanup Information System.

[12] United Nations Environmental Programme (2013) "Guidelines for National Waste Management Strategies Moving from Challenges to Opportunities”. ISBN 978-92-807-3333-4.

[13] Waste Management (2013). "Editorial Board/Aims \& Scopes”. Waste Management

34:IFC.doi:10.1016/so956-053x (14) 00026 - 9.

[14] www.who.int/water-sanitation-health/medicalwaste/unwantpharm.pdf

[15] www.usecology.com/services/field-services/pharmaceutical-waste-management.aspx 